\title{
Is the Experimental Auction a Dynamic Market?
}

\author{
Jay R. Corrigan*
}

November 2004

\begin{abstract}
Experimental auctions are generally thought of as static markets. This paper presents the results of an experimental auction designed to test whether participants' perceptions regarding the relative difficulty of delaying or reversing a transaction outside of the experimental market systematically affect their willingness-to-pay bids. The results show that auction participants' perceptions significantly impact their bids in a manner that is consistent with real option theory. These results suggest that economists must be careful to consider the existence of outside markets when designing experimental auctions.
\end{abstract}

Key words: experimental auctions, dynamic markets, real option theory, commitment cost.

JEL classifications: C91, D44, D81

\footnotetext{
* The author is assistant professor, Department of Economics, Kenyon College, Gambier, Ohio 43022, USA. Tel: 740-427-5281. Fax: 740-427-5276. E-mail: corriganj@kenyon.edu. The author was a visiting collaborator at the Center for Agricultural and Rural Development in Ames, Iowa while part of this research was completed. Thanks to Catherine Kling, John List, Matthew Rousu, Lise Vesterlund, and Jinhua Zhao for helpful comments, and to Christopher Burkart and Kevin Egan for help conducting the experiments. This paper has not been submitted elsewhere in identical or similar form, nor will it be during the first three months after its submission to the Publisher.
} 


\section{Is the Experimental Auction a Dynamic Market?}

Experimental auctions are now widely used in most fields of economics. Economists have, for example, used auctions to study the disparity between willingness to pay and willingness to accept payment (Kahneman et al. 1990; Shogren et al. 1994), to estimate the value individuals place on risk reduction (Shogren and Crocker 1994), and to estimate the effects of

market power in markets with few sellers (Davis and Williams 1991). Experimental auctions are perhaps most popular in estimating the value of new products or product traits, such as new packaging techniques (Hoffman et al. 1993), meat tenderness (Lusk 2001), and foods containing genetically modified ingredients (Rousu et al. 2004a).

These auctions are typically thought of as taking place in a static setting, in which case WTP is simply equivalent to the compensating variation (CV). The real world, however, is dynamic. If participants think of the experimental auction as part of a larger dynamic market, the equivalence between WTP and CV breaks down. WTP is instead equal to CV plus some dynamic component. Depending on auction participants' beliefs regarding the dynamic aspects of the market they are participating in, their WTP bids may either over- or understate their CV.

Several studies have argued that if auction participants believe the good up for auction can be purchased outside of the auction market for some price $p$, bids will be censored at or near p (Harrison 1992; Kolstad and Guzman 1999; Harrison et al. 2004). Cherry et al. (forthcoming) find this to be the case in both hypothetical and real auctions for induced value tokens. Zhao and Kling (2001, 2004) and Kling et al. (2003) go further, developing a model based on real option theory that shows that individuals' perceptions regarding their outside options may lead to WTP bids that either over- or understate their true valuation of a good. 
In this paper I report the results of an experimental auction designed to test whether WTP bids submitted in an experimental auction are systematically influenced by participants' perceptions regarding the relative difficulty of delaying or reversing a transaction. I find that these perceptions do in fact significantly affect WTP. This suggests that experimental auctions may not be static markets. Thus, ignoring the dynamic aspects inherent in these auctions may lead to misinterpretation of the resulting data. My results also have implications for the design of experimental auctions. For example, I show that seemingly equivalent demand revealing auction designs would not be expected to yield the same results if participants do indeed view the auctions as taking place within a larger dynamic market setting.

This paper proceeds as follows. In Section 1 I discuss the related theoretical literature. In Section 2 I lay out the design of an experimental auction intended to test whether participants' perceptions regarding the relative difficulty of delaying or reversing a transaction affect their WTP bids. Section 3 contains a discussion of the empirical results, which show that these perceptions significantly affect WTP. Conclusions follow in Section 4.

\section{Theoretical Background}

In order to better understand the dynamic nature of experimental auctions, I analyze participants' bidding behavior within the framework of the commitment cost model developed by Zhao and Kling $(2001,2004)$ and Kling et al. (2003). According to this model, if an agent faces uncertainty, the potential for future learning, and the possibility of limited reversal or limited delay, then the agent's WTP for a good in the current period is a function of both the good's expected value and a pair of option values. The first option value is associated with delaying the transaction, the second with immediate purchase. 
Given that the above conditions are met, delaying a transaction may allow the potential buyer to avoid a purchase that would yield negative surplus. Therefore, in order to commit to the purchase now and forgo future learning opportunities, the auction participant must be compensated by being offered a lower price than the one she would have been willing to pay in the absence of future learning. The difference between these two WTP figures is the option value associated with delay. ${ }^{1}$ There is also an option value associated with buying today, since this may allow the participant to sell the good for a profit at some future date. Thus, in a dynamic setting the participant's WTP is not simply equal to $\mathrm{CV}$, but is equal to $\mathrm{CV}$ plus a dynamic component made up of the difference between these two option values. Kling et al. (2003) develop a simple model of WTP incorporating the paired option values associated with any transaction made in a dynamic, uncertain setting. The authors show that the participant's willingness to pay can be written as

$$
W T P=C V+O V^{B u y}-O V^{\text {Delay }}
$$

where $C V$ is the compensating variation, $O V^{B u y}$ is the option value associated with immediate purchase, and $O V^{\text {Delay }}$ is the option value associated with delaying the transaction. Which of these option values is greater depends on the good's market price, the agent's own valuation of the good, and the perceived relative costs of purchasing or selling the item in the future. Other things being equal, an auction participant who perceives the cost associated with delaying the purchase to be greater than the cost associated with reversing it will submit a higher bid than a participant who believes reversal is relatively more costly. Thus, understanding a participant's perceptions regarding the relative difficulty of reversal versus delay is crucial in understanding whether her WTP bid is an over- or understatement of her CV. 
Results from a field experiment conducted by Kling et al. (2003) show that WTP for sportscards at a sportscard convention is affected by the buyers' perceptions regarding the relative difficulty of reversal and delay in a manner that is consistent with the commitment cost model. ${ }^{2}$ This is reassuring but not terribly surprising given that the transactions were taking place in a real, well-functioning, dynamic market setting. In order to understand whether dynamic perceptions affect WTP bids submitted in experimental auctions (a market environment typically thought of as static), it is necessary to gauge the effects of participants' perceptions on bids submitted within the confines of the experimental auction.

\section{Experimental Design}

Participants in this study were recruited from Principles of Economics courses at Iowa State University during the spring of 2002. ${ }^{3}$ Thirty students took part in each of two experimental units, for a total of sixty participants. Each student received $\$ 15$ for participating.

The experiment had six steps. ${ }^{4}$ During the first step, participants read along as the monitor read the instructions aloud. These instructions contained a brief introduction to the experiment, as well as a detailed description of the workings of the random $n$ th-price auction (Shogren et al. 2001). The monitor also went over an example auction on the blackboard and administered a short quiz to test participants' understanding of the auction mechanism. The instructions borrowed their description of the auction mechanism from Shogren et al. (2001).

The second step was a non-binding practice auction for a dollar bill. This auction was intended to further familiarize participants with the auction mechanism. The monitor collected the bids and ranked them on the blackboard, then announced the randomly-determined $n$th 
price. ${ }^{5}$ Participants were then informed that, had this been a real round, anyone who submitted a bid above the $n$th price would buy a dollar bill.

During step three, the monitor informed participants that the following two auction rounds would be for Iowa State University-logo coffee mugs, but that only one of the two rounds would be binding, and that the binding round would be determined by a coin flip after both rounds had been completed.

In step four, participants inspected the mugs being auctioned off and submitted a bid indicating their maximum WTP for such a mug. The mugs were clearly marked with a bookstore price tag (\$5.95). In different experiments, Kahneman, Knetsch, and Thaler (1990) auctioned off coffee mugs with and without price tags and found similar results in both cases. I chose to leave the price tags on the mugs in order to eliminate uncertainty about the mugs' outside market price. After submitting their bids, participants completed a survey designed to collect data about their age, gender, and income, as well as their perceptions regarding the relative difficulty of selling or buying the mug outside of the experiment. Upon completion, the monitor collected these surveys.

During step five, participants submitted a second bid indicating their maximum WTP for the mug. After submitting these bids, they completed a second perceptions survey similar to the first, but excluding questions on age, gender, and income. The monitor collected these surveys once all participants had completed them. ${ }^{6}$

In step six, the monitor determined the binding round by flipping a coin. After announcing the result of the coin flip, the monitor ranked the bids from the binding round on the blackboard, and determined and announced the random $n$th price. Participants were informed 
that if they had submitted a bid above this price, they would purchase a mug at the $n$th price. Participants were then paid \$15 for participating, and any transactions agreed to were carried out.

In the context of this study, the commitment cost model predicts that bids submitted by participants who believe that selling outside the experiment is relatively difficult will, on average, be lower than those submitted by participants who believe that buying outside is relatively difficult.

\section{Empirical Results}

In this section, I begin by comparing participants' bids with their perceptions of the relative difficulties of reversal versus delay. I then describe the results from a regression designed to test for the effects these perceptions have on WTP. Examination of the data shows that participants' perceptions of the market's dynamic features have a statistically significant impact on their WTP bids.

Table I presents the summary statistics from the practice auction and the first potentially binding auction round. Table II reports mean WTP bids conditional on participants' reported perceptions of the relative difficulty of reversal versus delay. As predicted, buyers who perceived reversal (i.e., selling the good outside of the experiment) to be more difficult than delay (i.e., buying the good outside of the experiment) submitted bids significantly lower than buyers who perceived reversal to be easier than delay ( $\$ 2.26$ versus $\$ 3.86, t=2.15$ ).

To further assess the results, I also use regression analysis to estimate WTP as a function of participants' perceptions. I consider the following specification:

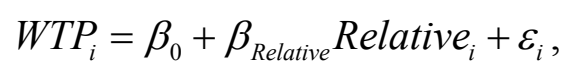


where $\varepsilon_{i}$ is a mean-zero error term, and Relative ${ }_{i}$ is defined as the difference between participant $i$ 's perceived difficulty of selling later and her perceived difficulty of buying later. That is,

$$
\text { Relative }_{i}=\frac{1}{4}\left(\text { SellDifficulty }_{i}-\text { BuyDifficulty }_{i}\right) \text {, }
$$

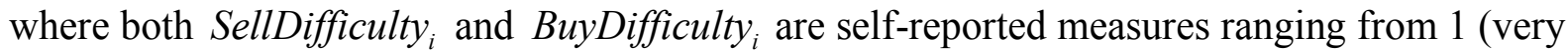
easy) to 5 (almost impossible). ${ }^{7}$ If, for example, participant $i$ reports that she believes that selling outside the experiment would be almost impossible but that buying would be very easy, then Relative $_{i}=1$. The estimate of $\beta_{\text {Relative }}$ reported in Table III is significantly less than zero $(t=-2.49)$. This suggests that potential buyers who believe selling later (reversal) will be more difficult than buying later (delay) tend to bid significantly less than those who believe selling later will be relatively easy. ${ }^{8}$ This relationship can also be seen in Figure 1 which plots participants' bids versus their perceptions regarding the relative difficulty of reversal and delay. These findings strongly suggest that WTP bids submitted in experimental auctions contain a dynamic component, even when participants are bidding on a familiar good whose outside market price is known.

\section{Discussion and Conclusions}

Auctions conducted in an experimental setting are often the most convenient way to estimate consumers' willingness to pay for new products or product traits. For example, experimental auctions have been used to estimate consumers' valuation of new packaging techniques (Hoffman et al. 1993), irradiated meat (Hayes et al. 1995; Fox et al. 2002), meat tenderness (Lusk 2001), and food safety information provided by environmental groups (Rousu 
et al. 2004b). While experimental auctions are typically thought of as taking place in a static market, uncertainty and the potential for delay and/or reversal are often inherent and inescapable aspects of these markets. If this is the case, researchers may not be estimating compensating variation (which is, presumably, what they are interested in), but compensating variation plus a dynamic component made up of the difference between option values associated with delay and reversal.

To understand how the existence of such option values might affect the results of experimental auctions, consider two similar techniques for estimating the value of some new product trait. Economists often estimate WTP for a new trait either by endowing auction participants with a conventional product and then giving them the opportunity to bid to upgrade to a product possessing the trait of interest (e.g., Shogren et al. 1994, 2000; Lusk 2001), or by eliciting WTP bids for both products separately and then taking the difference between the two bids (e.g., Noussair et al. 2002, 2004; Rousu et al. 2004a, 2004b). While in a static setting either of these techniques should yield unbiased estimates of the value participants place on the new product trait, both techniques may either over- or understate the trait's value in a dynamic setting. 9

For example, suppose two products are being sold in an experimental auction: conventional farm-raised salmon and salmon which has been farm raised in accordance with the USDA's organic labeling requirements. Assume it is common knowledge that the costs associated with reselling either product outside of the auction are prohibitively high, and that while it is impossible to purchase organic farm-raised salmon outside of the auction environment, conventional farm-raised salmon can be purchased at any supermarket. Under these conditions, if the experimenter endows participants with one pound of conventional salmon 
and then allows them to bid to exchange that for one pound of organic salmon, WTP bids would simply equal the difference between participants' CV for each product. That is,

$$
\text { Bid }=C V_{\text {Org }}-C V_{\text {Con }} \text {, }
$$

where $C V_{\text {Org }}$ is that associated with organic farm-raised salmon and $C V_{C o n}$ is that associated with the conventional farm-raised variety. Given the participants' beliefs, bidding can truly be thought of as taking place in a static setting because participants cannot delay or reverse the transaction.

Alternatively, if the experimenter endows participants with nothing, but gives them the opportunity to place separate bids for both types of salmon, the new product trait's value would be calculated by taking the difference between the two bids. That is,

$$
\text { Bid }_{\text {Org }}-\text { Bid }_{\text {Con }}=C V_{\text {Org }}-\left(C V_{\text {Con }}-O V_{\text {Con }}^{\text {Delay }}\right)
$$

where $O V_{C o n}^{\text {Delay }}$ is the option value associated with delaying the purchase of the conventional salmon. Since it can be shown that $O V_{\text {Con }}^{\text {Delay }}$ is nonnegative, the value of the new trait will be overestimated if the valuation process is indeed dynamic. And since even participants who regularly buy salmon outside of the experimental environment may not know the current market price, delaying any purchase until they can find out more about the product's price outside of the experiment will allow them to avoid overpaying today (Kolstad and Guzman 1999). Thus, if the cost associated with delaying the purchase of conventional salmon is thought to be sufficiently low, $O V_{C o n}^{\text {Delay }}$ may be positive even if participants are certain about the value they would derive from consuming the conventional salmon.

Given this set of assumptions about the potential for outside reversal and delay, an experimenter interested in estimating only the value participants place on the organic-label trait 
should endow the participants with the conventional salmon and then allow them to bid to upgrade.

It is also important to note that it is the perceived relative difficulty of delay and reversal that determine the magnitude of the dynamic component. In the above example, if a participant incorrectly believed that organic farm-raised salmon could be purchased outside of the experimental auction, her bid to upgrade to organic salmon if she were endowed with conventional farm-raised salmon would be

$$
\text { Bid }=\left(C V_{\text {Org }}-O V_{\text {Org }}^{\text {Delay }}\right)-C V_{C o n}
$$

Since it can be shown that $O V_{O r g}^{\text {Delay }}$ is nonnegative, this design could lead to an underestimate of the trait's value. In this example, it is imperative that participants accurately perceive the market's dynamic characteristics.

In this paper, I have discussed an experimental auction designed to test whether participants' WTP for a familiar good is affected by their perceptions of the experimental market's dynamic aspects. I find that potential buyers' perceptions regarding the relative difficulty of outside reversal and delay do significantly affect WTP. Specifically, participants who believe delaying a transaction will be relatively difficult submit bids significantly higher than participants who believe delay will be relatively easy. These results suggest that researchers designing experimental auctions must recognize that those auctions may in fact be taking place within a larger dynamic market setting. It is also important that auction participants have an accurate understanding of the market setting's dynamic aspects. 


\section{Notes}

${ }^{1}$ Strictly speaking, this difference is not an option value but a commitment cost. An option value refers to a one-time wealth transfer, whereas a commitment cost refers to a permanent change in price. However, since the option value concept is much more widely known, in this paper I adopt the naming convention used in Kling et al. (2003), and refer to the difference as an option value.

${ }^{2}$ For counter results see Lusk (2003).

${ }^{3}$ In order to avoid problems associated with participants behaving in such a way as to please their instructor, the instructors of these courses were in no way involved with this research and were not present when the experimental auctions were conducted.

${ }^{4}$ The complete instructions given to participants are available from the author upon request. 5 To determine the $n$th price the monitor first ranks participants' bids from highest to lowest, then randomly selects a number between 2 and $N$ (where $N$ is the number of participants). The bid corresponding to that number is the $n$th price. By separating what participants bid from what they pay if they win the auction, the random $n$ th-price auction mechanism preserves the demandrevealing properties of the Vickrey auction. Shogren et al. (2001) show that the random $n$ thprice auction outperforms the Vickrey auction mechanism in motivating off-margin bidders to bid their true valuation in an auction for induced value tokens.

${ }^{6}$ The results from the second potentially binding auction round were used as part of a different study focusing on WTA-WTP disparity and are not discussed in this paper.

7 The format of these questions was similar to that used by Kling et al. (2003).

${ }^{8}$ A similar regression that included participants' age, gender, and income yielded qualitatively similar results. In particular, the coefficient $\beta_{\text {Relative }}$ was still negative and significant at the 0.05 level $(t=-2.07)$. Of the coefficients associated with the socioeconomic variables, only the income coefficient was significantly different from zero $(t=2.51)$.

${ }^{9}$ For further discussion of how initial endowments affect WTP bids in experimental auctions see Corrigan and Rousu (2004) and Lusk et al. (2004). 


\section{References}

Cherry, T., P. Frykblom, J. List, J. Shogren and M. Williams (forthcoming), 'Laboratory Testbeds and Nonmarket Valuation: The Case of Bidding Behavior in a Second Price Auction with an Outside Option,' Environmental and Resource Economics.

Corrigan, J. and M. Rousu (2004), 'The Effect of Initial Endowments in Experimental Auctions,' working paper, Kenyon College.

Coursey, D., J. Hovis and W. Schulze (1987), 'The Disparity Between Willingness to Accept and Willingness to Pay Measures of Value,' Quarterly Journal of Economics 102, 679-90.

Davis, D. and A. Williams (1991), 'The Hayek Hypothesis in Experimental Auctions: Institutional Effects and Market Power,' Economic Inquiry 29, 261-74.

Fox, J., D. Hayes and J. Shogren (2002), 'Consumer Preferences for Food Irradiation: How Favorable and Unfavorable Descriptions Affect Preferences for Irradiated Pork in Experimental Auctions,' Journal of Risk and Uncertainty 24, 75-95.

Hayes, D., J. Shogren, S. Shin and J. Kliebenstein (1995), 'Valuing Food Safety in Experimental Auction Markets,' American Journal of Agricultural Economics 77, 40-53.

Harrison, G. (1992), 'Theory of Misbehavior of First-Price Auctions: Reply,' American Economic Review 82, 1426-43.

Harrison, G., R. Harstad and E. Rutström (2004), 'Experimental Methods and Elicitation of Values,' Experimental Economics 7, 123-40.

Hoffman, E., D. Menkhaus, D. Chakravarti, R. Field and G. Whipple (1993), 'Using Laboratory Experimental Auctions in Marketing Research: A Case Study of New Packaging for Fresh Beef,' Marketing Science 12, 318-338. 
Kahneman, D., J. Knetsch and R. Thaler (1990), 'Experimental Tests of the Endowment Effect and the Coase Theorem,' Journal of Political Economy 98, 1325-48.

Kolstad, C. and R. Guzman (1999), 'Information and the Divergence between Willingness to Accept and Willingness to Pay,' Journal of Environmental Economics and Management 38, 66-80.

Kling, C., J. List and J. Zhao (2003), 'Commitment Cost and the Basic Independence Assumption: Evidence from the Field,' working paper, Iowa State University.

Lusk, J. (2001), 'In-Store Valuation of Steak Tenderness,' American Journal of Agricultural Economics 83, 539-50.

Lusk, J. (2003), 'An Experimental Test of the Commitment Cost Theory,' American Journal of Agricultural Economics 85, 1316-22.

Lusk, J., T. Feldkamp and T. Schroeder (2004), 'Experimental Auction Procedure: Impact On Valuation of Quality Differentiated Goods,' American Journal of Agricultural Economics 86, $389-405$.

Noussair, C., S. Robin and B. Ruffieux (2002), 'Do Consumers Not Care About Biotech Foods or Do They Just Not Read the Labels?,' Economics Letters 75, 47-53.

Noussair, C., S. Robin and B. Ruffieux (2004), 'Do Consumers Really Refuse to Buy Genetically Modified Food?,' Economic Journal 114, 102-20.

Rousu, M., W. Huffman, J. Shogren and A. Tegene (2004a), 'Are United States Consumers Tolerant of Genetically Modified Foods?,' Review of Agricultural Economics 26, 19-31. Rousu, M., W. Huffman, J. Shogren and A. Tegene (2004b), 'Estimating the Public Value of Conflicting Information: The Case of Genetically Modified Foods,' Land Economics 80, 125-35. 
Shogren, J. and T. Crocker (1994), 'Rational Risk Valuation Given Sequential Reduction Opportunities,' Economics Letters 44, 241-48.

Shogren, J., S. Shin, D. Hayes and James B. Kliebenstein (1994), 'Resolving Differences in Willingness to Pay and Willingness to Accept,' American Economic Review 84, 255-70.

Shogren, J., J. List and D. Hayes (2000), 'Preference Learning in Consecutive Experimental Auctions,' American Journal of Agricultural Economics 82, 1016-21.

Shogren, J., M. Margolis, C. Koo and J. List (2001), 'A Random $n$ th-Price Auction,' Journal Of Economic Behavior And Organization 46, 409-21.

Vickrey, W. (1961), 'Counterspeculation, Auctions, and Competitive Sealed Tenders,' Journal of Finance 16, 8-37.

Zhao, J. and C. Kling (2001), 'A New Explanation for the WTP/WTA Disparity,' Economics Letters 73, 293-300.

Zhao, J. and C. Kling (2004), 'Willingness to Pay, Compensating Variation, and the Cost of Commitment,' Economic Inquiry 42, 503-17. 
Table I. WTP Bid Descriptive Statistics $(n=60)$

\begin{tabular}{cccc}
\hline \hline & Mean & Median & Standard Deviation \\
\hline Dollar Bill & 0.97 & 0.99 & 0.42 \\
Coffee Mug & 2.42 & 2.00 & 1.75 \\
\hline \hline
\end{tabular}


Table II. The Effects of Perceived Differences in Relative Reversal and Delay Difficulty

\begin{tabular}{ccc}
\hline \hline Perceived Relative Difficulty & Mean Bid & Observations \\
\hline Reversal Difficulty & 2.26 & 43 \\
> Delay Difficulty & $(1.72)^{\mathrm{a}}$ & 11 \\
Reversal Difficulty & 2.26 & \\
= Delay Difficulty & $(1.76)$ & 6 \\
Reversal Difficulty & 3.86 & \\
< Delay Difficulty & $(1.58)$ & \\
\hline \hline
\end{tabular}

${ }^{a}$ Numbers in parentheses are standard deviations. 
Table III. Regression Results

\begin{tabular}{cc}
\hline \hline Parameter & Estimate \\
\hline$\beta_{0}$ & $2.91^{* * *}$ \\
& $(7.56)^{\mathrm{a}}$ \\
$\beta_{\text {Relative }}$ & $-1.37^{* *}$ \\
& $(-2.49)$ \\
\hline \hline
\end{tabular}

${ }^{a}$ Numbers in parentheses are $t$ statistics.

** Significant at the 0.05 level.

*** Significant at the 0.01 level. 
